\title{
Geography matters to disability: regional disparity of bathing difficulty among older adults in China
}

\author{
Jasmon W. T. Hoh ${ }^{1} \cdot$ Qiushi Feng ${ }^{1,2}$
}

Received: 14 August 2021 / Accepted: 26 October 2021 / Published online: 18 November 2021

(C) The Author(s) 2021

\begin{abstract}
Bathing is a major type of disability among older adults. While studies on bathing difficulties have recently started to go beyond the limitations of the human body to examine bathroom amenities; researchers have rarely considered the environment beyond the bathroom. This study explored the regional disparities in bathing disability among older adults in China. Using data from the Chinese Longitudinal Healthy Longevity Survey from 1998 to 2018, random-effects logistic regressions were performed to examine how bathing difficulties differed across regions among older adults in China. We found that older adults residing in the northern regions were significantly more likely to experience bathing disability compared to those from the South after controlling for confounding variables. Women and the oldest-old were also the most likely to experience bathing disabilities. Within the Northern regions itself, individuals from the Northeast stood out for having the highest likelihood of experiencing bathing disability. Interestingly, this regional disparity only existed for bathing disability and not the other Activities of Daily Living (ADL) items. It is concluded that the large regional disparity could be due to both climate differences and uneven economic development across the different regions in China. As bathing is a highly environment-dependent activity, this study highlights the potential for policy interventions to reduce the prevalence of bathing disability among older adults through improving the bathing environment. Additionally, we aim to put forth the notion that disability research should move towards analyses of specific disability items rather than an undifferentiated ADL index.
\end{abstract}

Keywords ADL $\cdot$ China $\cdot$ Older adults $\cdot$ Bathing $\cdot$ Region $\cdot$ Environment

Qiushi Feng

socfq@nus.edu.sg

1 Department of Sociology, National University of Singapore, Singapore, Singapore

2 Centre for Family and Population Research (CFPR), National University of Singapore, AS1 04-30, Arts Link, Singapore 117570, Singapore 


\section{Introduction}

China has the world's largest group of older adults, with approximately 264 million older adults aged 60 and over, comprising nearly $20 \%$ of its total population (National Bureau of Statistics of China, 2021). One central concern about population aging for China is the relatively high rates of functional limitation and disability in older adults, which have significant implications on long-term care insurance and healthcare spending (Chen et al., 2020; Waidmann \& Liu, 2000). According to the World Health Organization (World Health Organization, 2015), around 40 million Chinese older adults are estimated to be functionally disabled. More work is needed to understand the factors causing physical disability, especially given the recent unveiling of the ambitious national plan "Healthy China 2030" (Tan et al., 2017).

Activities of daily living (ADL) is the most commonly used measurement for physical disability. Specifically, it refers to a series of basic self-care activities (bathing, dressing, toileting, transferring, continence, feeding) critical to daily functioning (Katz et al., 1963). The ability to perform these activities without assistance is often used to indicate the level of physical functioning in older adults (Gu \& Zeng, 2004; Zhang \& Feldman, 2020). Although physical impairment is often considered as the base of disability, it has long been acknowledged that ADL disability is caused by both a mixture of body limitations and environmental barriers (Verbrugge \& Jette, 1994; World Health Organization, 2015). Environmental factors could play an important role in influencing the outcome of ADL tasks (De-Rosende-Celeiro et al., 2019; Iwarsson, 2005; Lim et al., 2020). In the World Report on Disability, special emphasis is placed on how environmental factors such as the built environment, social support, and policies can facilitate access or create barriers that affect participation, strengthening the need for existing disability studies to examine both the human body as well as its interactions with the environment (World Health Organization, 2011).

Recent studies have started to pay more attention to how environmental factors affect specific ADL disabilities, in particular about toileting difficulties. For example, a recent paper by Fong and Feng (2021) found that environmental factors, such as the presence of flush systems and the need to share toilets with other households, could at least partially explain the variation in the toileting difficulties among older adults in China. Similarly, another study that examined toileting disability noted that different toileting environments such as the use of pedestal pan indoors or outdoors toileting could significantly affect the likelihood of functional disability in Chinese rural residents of old ages (Liu et al., 2020). These studies have strong implications that policy interventions to modify the toileting environment could be effective in reducing the prevalence of functional disability among older adults in China.

Along this line of research, this study examined another important ADL item, bathing at advanced ages. Within the hierarchy of activity complexity among ADL items (Katz \& Akpom, 1976), bathing tends to be the most complex, requiring substantial coordination between the upper and lower limbs ( $\mathrm{Gu} \& \mathrm{Xu}, 2007$; 
Jagger et al., 2001; Murphy et al., 2007). Comparing bathing and feeding, for instance, while the bathing task would inherently involve more complex body movements such as bending down, turning around, or reaching around the body, feeding may only require limited upper-body movements (Cohen-Mansfield \& Parpura-Gill, 2007). More importantly, like toileting, bathing is also highly sensitive to the environment (climate and temperature) and facilities available (such as standing/sitting showers, bathtubs, outdoor showering facilities), which could greatly affect the body movements required in bathing (Rader et al., 2006). Because of the movement-complexity and environmental-sensitivity, bathing disability is often one of the most prevalent types of ADL disability among older adults (Purser et al., 2012) and its dependence on the environmental factors meant that there is significant potential for interventions to target.

Studies specifically exploring the relationship between bathing disability and environmental factors are scarce, and most of the literature on bathing disability has been focused on the interventions inside the modern bathroom through the use of assistive technologies such as grab rails and bath transfer benches (Aminzadeh et al., 2001; DeRosende-Celeiro et al., 2019; Gill et al., 2007; Naik \& Gill, 2005). It is worth noting that a recent study by Liu et al. (2020) reported that Chinese rural older adults may have up to four bathing methods (such as showering indoors, bathing indoors, use of public bathing facilities, or bathing outdoors), unlike their urban counterparts for whom bathroom facilities are usually modernized and standardized. However, to our knowledge, no studies in the field have examined regional disparity of bathing among older adults in China, though the current literature clearly demonstrates that physical disability is closely associated with environmental factors such as air pollution (Lv et al., 2020), temperature (Zeng et al., 2010), as well as neighborhood conditions (Balfour \& Kaplan, 2002; Freedman et al., 2008).

We aim to fill this research gap by exploring the aforementioned regional disparity in China. Owing to its large land area, in regard to climate features, China could be divided into Northern or Southern regions with Northern parts of China being significantly colder than its Southern counterparts (Hua et al., 2008; Si et al., 2014). On the other hand, development studies often divide China into four geographical regions (Northeast, Central, East, West) that reflect common levels of socioeconomic development (Liu \& Zhang, 2019; Wu et al., 2019). The Eastern regions fare better economically than their Central or Western counterparts, while the Western regions remain relatively more under-developed than the Central regions of China (He et al., 2017; Shen et al., 2018). This study adopts a two-level scheme of regional divisions for China, greater north (Northwest, North, Northeast) versus greater south (East, Central, South, Southwest), which would better reflect not only the difference in climate between regions but also socioeconomic differences. 


\section{Method}

\subsection{Data}

The present study used data from eight waves of the Chinese Longitudinal Healthy Longevity Survey (CLHLS) conducted in 1998, 2000, 2002, 2005, 2008, 2011, 2014, and 2018. CLHLS is a nationally representative longitudinal survey that collects extensive information on the health statuses, sociodemographic characteristics, and lifestyle behavior of older adults in China (Zeng, 2012). The survey initially covered 22 out of 31 provinces in China, where it represented around $85 \%$ of China's total population. Hainan province was subsequently added from the fifth wave onwards in 2008, bringing the total up to 23 provinces. Roughly half of the counties and cities in each province were then randomly selected and sampled from. The initial 1998 baseline survey conducted face-to-face interviews with approximately 9000 respondents aged 80 and over. In the follow-up waves of the survey, survivors were re-interviewed while new respondents were recruited to replenish those that were lost either to death or other reasons. From 2002 onwards, the sampling frame was also expanded to include younger respondents from age 65-79. Various assessments of data quality examining the reliability and validity of measures had been conducted for earlier waves of the survey and they were found to be of overall good quality (Gu et al., 2021).

We pooled data from all eight waves of the CLHLS, obtaining 99,412 observations from 56,459 respondents initially. For the analysis, we excluded 44 duplicated observations and 482 observations with missing data about bathing disability. To concentrate our attention on older adults, we further narrowed our analysis to respondents between the age of 65-99. Centenarians were excluded as studies have found that they generally exhibit significantly different health patterns compared to other older adults due to a combination of genetic and environmental factors (Hoh et al., 2021; Moskalev et al., 2014; Vacante et al., 2012).

Multiple imputations by chained equations was chosen to address missing data in this study. As outlined in Azur et al. (2011), this method operates under the assumption that data were missing at random, and that observed values can fully explain the differences between missing and observed data. The method was also found to produce less biased and higher quality estimates as compared to using complete case analysis or other single imputation methods (Ambler et al., 2007). In total, five multiple imputed datasets were generated and subsequently analyzed using a model that included the imputation of all the variables detailed in this study, including the dependent variable.

\subsection{Measurements}

The main dependent variable was bathing disability. Respondents of CLHLS were asked to indicate whether they required assistance in bathing for two or more parts of their body, required assistance for one part of their body, or do not require 
assistance in bathing at all. Building upon previous literature (Lv et al., 2018; Purser et al., 2012), we dichotomized the variable such that respondents who indicated that they required assistance in bathing were considered ADL-disabled in bathing.

The primary independent variable of interest was the geographical regions of China. The 23 provinces in China where the survey took place included Anhui, Beijing, Chongqing, Fujian, Guangdong, Guangxi, Hainan, Hebei, Heilongjiang, Henan, Hubei, Hunan, Jiangsu, Jiangxi, Jilin, Liaoning, Shaanxi, Shandong, Shanghai, Shanxi, Sichuan, Tianjin, and Zhejiang. These provinces could be classified into the two-level schemes of regional divisions as shown in Table 1.

We comprehensively controlled the individual-level factors to address confounding effects. Three groups of covariates are included in the study, namely the socioeconomic variables, health status variables, and health behavior variables. The sociodemographic variables included age, gender (men or women), residential status (urban or rural), education (measured by years of education), logged household income, marital status (married or not married), and number of coresidents. We also added the variable occupational prestige, which was measured based on the main occupation of the respondent before age 60 (Treiman, 1977).

Next, we considered various variables of health status. As reflected in previous literature (Yin et al., 2020; Zhu et al., 2017), an index of negative affect was used as a measure of depressive symptoms, including loneliness ("do you often feel lonely and isolated?"), neuroticism ("do you often feel fearful or anxious?"), and loss of self-worth ("do you feel the older you get, the more useless you are?"). We used the sum of the three items, with higher scores indicating higher negative well-being (Cronbach's $\alpha=0.59$ ). As the alpha value is relatively low, a supplementary sensitivity analysis that considered the three items separately was also performed, but only negligible differences were found. Cognitive impairment was measured by the Chinese version of the Mini-Mental State Examination (MMSE), with scores ranging from 0 to 30. Participants with scores lower than 18 were treated as cognitively impaired (Gao et al., 2017; Zeng et al., 2017; Zhang et al., 2008). As bathing difficulty is highly affected by functional limitations, we further added the variables upper limb functional limitation and lower limb functional limitation. Upper limb functional limitation is a binary variable, based on the test of putting both hands behind the neck and lower back. Lower limb functional limitation is similarly a

Table 1 Grouping of provinces in China into geographical regions

\begin{tabular}{lll}
\hline North-South & Regions & Provinces \\
\hline Greater north & Northwest & Shaanxi \\
& North & Beijing, Tianjin, Hebei, Shanxi \\
& Northeast & Liaoning, Jilin, Heilongjiang \\
Greater south & East & Shanghai, Jiangsu, Zhejiang, \\
& & Anhui, Fujian, Jiangxi, \\
& & Shandong \\
& Central & Henan, Hubei, Hunan \\
& South & Guangdong, Guangxi, Hainan \\
& Southwest & Chongqing, Sichuan \\
\hline
\end{tabular}


binary variable, based on the tests of standing up from a chair without using hands and turning $360^{\circ}$ without assistance.

Lastly, we also controlled for four health behavior variables. Firstly, dietary risk factors were measured by the regular consumption of vegetables and fruits, coded as 1 if the respondent indicated that he/she consumes vegetables or fruits "Almost every day" or "Often". To assess physical activity levels, we coded 1 if the respondent answered "Yes" to the question "Do you do exercise regularly at present?". For smoking, we coded 1 if the respondent answered "Yes" to either "Do you smoke in the past? or "Do you smoke at present time?". Lastly, the level of engagement in leisure and social activities was also measured (see Monma et al., 2016; Sun, 2021). Overall, five leisure activities (gardening, reading newspaper/books, playing cards/mahjong, watching TV/listening to the radio, and engaging in organized social/religious activities) were considered and we coded 1 for each activity if the respondent engaged in the activity at least occasionally. The level of engagement is represented by the sum of all the activities engaged (ranging from 0 to 5). Finally, we controlled for each year that the survey was administered.

\subsection{Analytical strategy}

First, we performed a series of descriptive analyses to compare regions of China in terms of bathing disability prevalence. Then, we expanded such regional comparisons to other ADL disabilities (dressing, toileting, transferring, continence, feeding) in order to examine if the regional patterns of bathing disability could be applicable to other ADL disabilities. Due to the unique design of CLHLS, all prevalence was estimated using the weighting methods recommended by the CLHLS team.

Next, we used random-effects logit models to investigate the relationship between the geographical region of residence and bathing disability experienced by older adults in China. This is to account for the intra-personal covariance due to the repeated observations in the longitudinal survey of CLHLS. In the regression analyses, we used stepwise regression to examine the role of various explanatory variables in affecting the bathing disability of older adults in China. Model I included the north-south region variable, which is the main variable of interest, as well as other sociodemographic variables. Model II added health status variables and Model III further controlled for health behavior variables. Additional sets of regression analysis are then separately performed for men and women, as well as between the younger-old and the oldest-old as previous studies on disability trends have reported differences between age groups and genders (Feng et al., 2013; Zhang, 2006). For the above analyses, we separated the greater north and south regions, and we further do the same sets of analysis with the smaller subset of seven separate regions (Northwest, North, Northeast, East, Central, South, Southwest). This will help us to better understand the regional disparity. The models have all been adjusted for the survey year. All statistical analyses in this study were performed using Stata 13. 


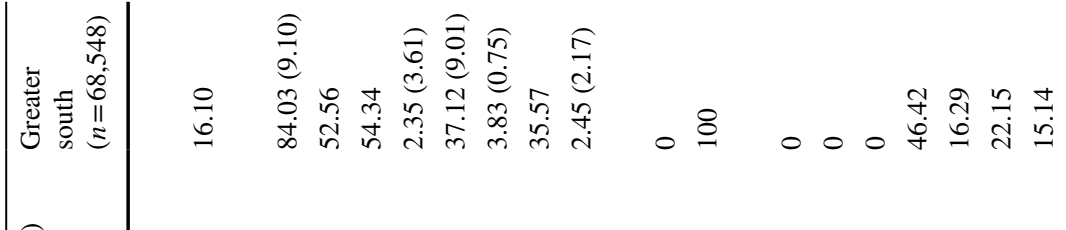

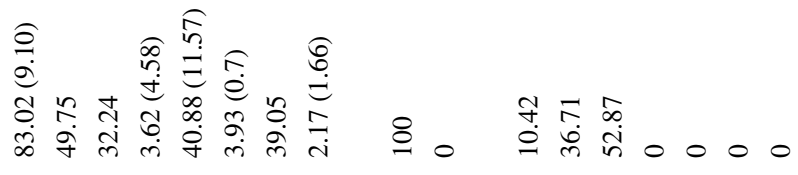

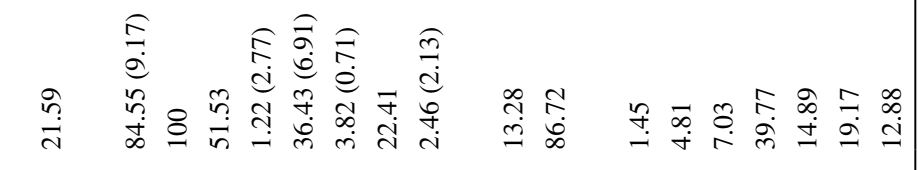

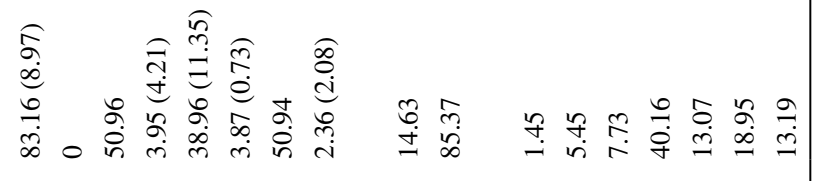

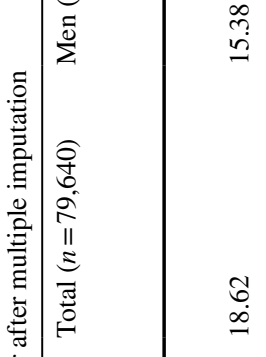

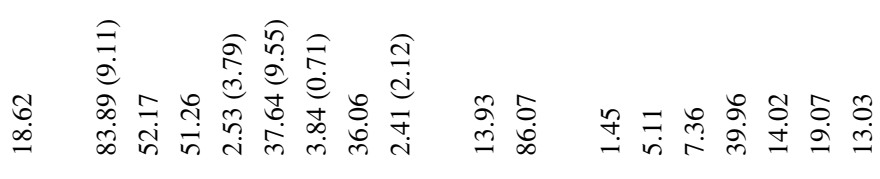

$$
\begin{aligned}
& \text { 离 }
\end{aligned}
$$

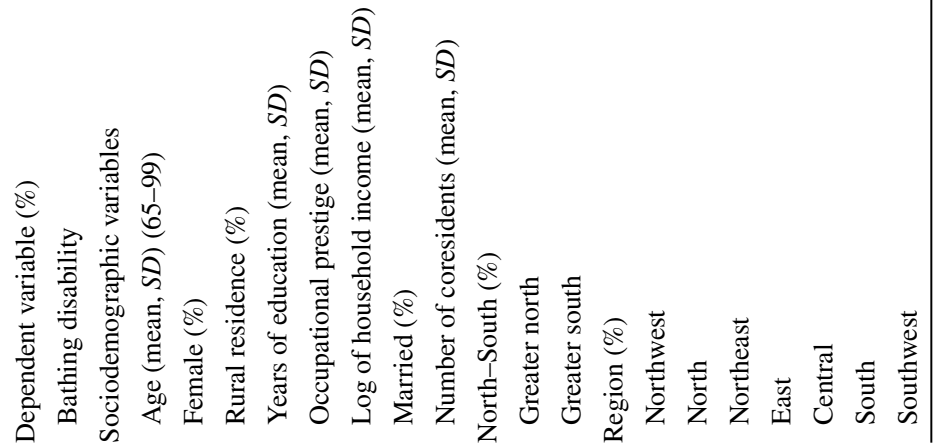




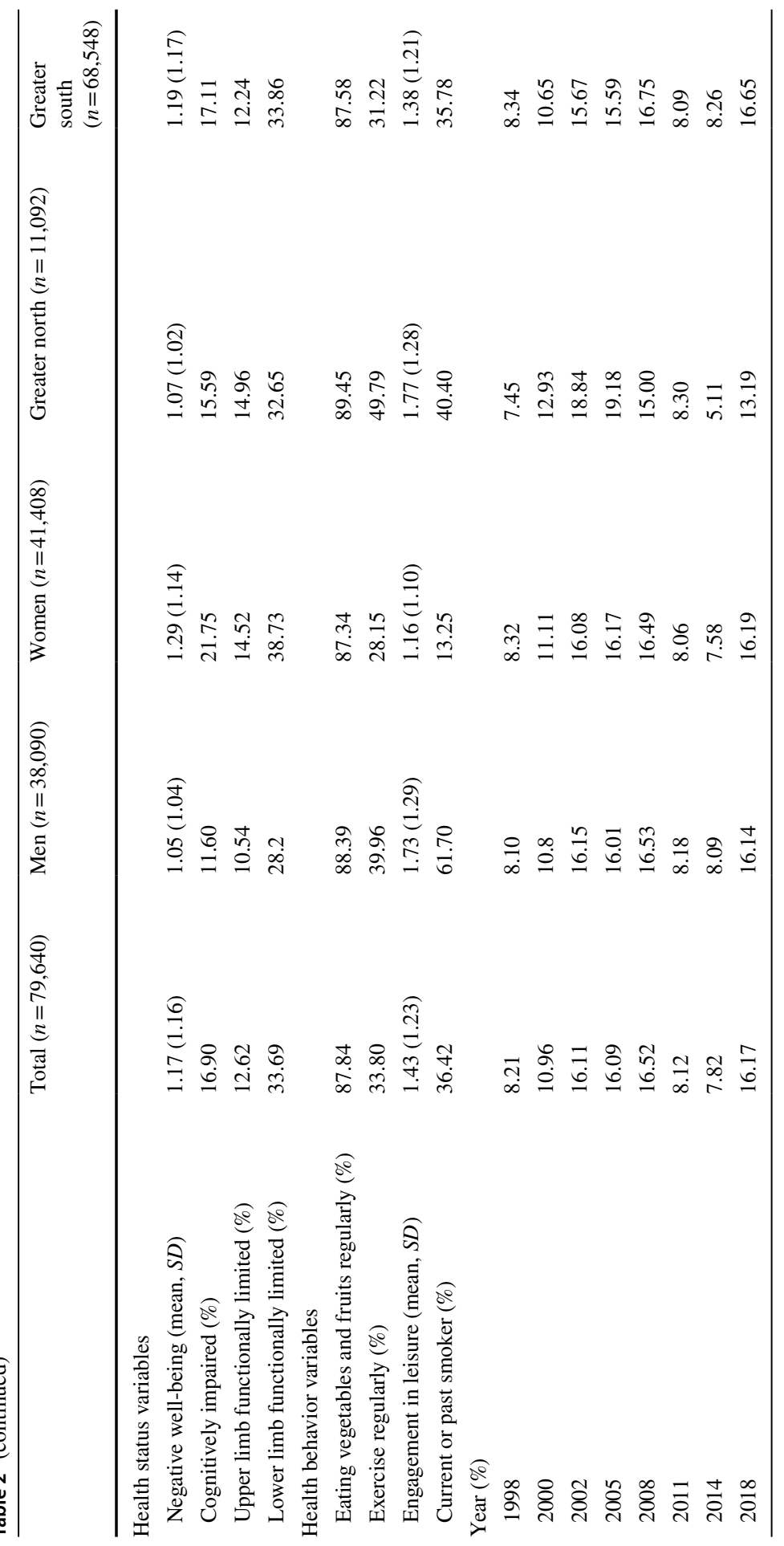




\section{Results}

Table 2 provides the descriptive statistics of the sample after multiple imputation was performed. The final analytic sample consisted of 79,640 observations from 42,804 individuals. The average age of the sample was between 83 and 85 years old across the eight waves of the survey. The distribution of gender was approximately balanced, with slightly more observations from women $(n=41,408)$ than men $(n=38,016)$ in the sample. On average, women experienced higher levels of bathing disability $(21.57 \%$ ) compared to men $(15.36 \%)$, while faring worse on socioeconomic index and health statuses. Along the north-south divide, approximately $14 \%$ of the sample was classified as being located in the greater north regions, which included the northwest, north, and northeast regions. The largest contributor to the sample came from the east region, where roughly $40 \%$ of the respondents in the sample resided.

The left panel of Fig. 1 shows the prevalence of bathing disability across the seven geographical regions in China for older adults aged 65-99. As expected, bathing disability, as shown in the figure, increased with age. However, there was significant regional disparity: bathing disability was much higher at each age for individuals from the three northern regions compared to the southern regions. To better illustrate this, we took a step further to smoothen the pattern and highlight the north-south contrast in the right panel of Fig. 1. The disparity in bathing disability was clear between north and south, and it even widened as it approached the oldestold age range.

We further examined if the north-south pattern of regional disparity was also applicable to other ADL disabilities such as dressing, toileting, transferring, continence, and feeding (Fig. 2). It is interesting to note that only bathing disability had an especially high prevalence and stark disparity between the north and south, whereas for some other ADL disabilities, it seems that there were only slight north-south disparities at the oldest-old ages.

Table 3 presents the results of the random-effects logistic regression examining the relationship between bathing disability of older adults and other predictors in a stepwise format. Model I shows that residing in the greater north region of China significantly increased the risk of experiencing bathing disability
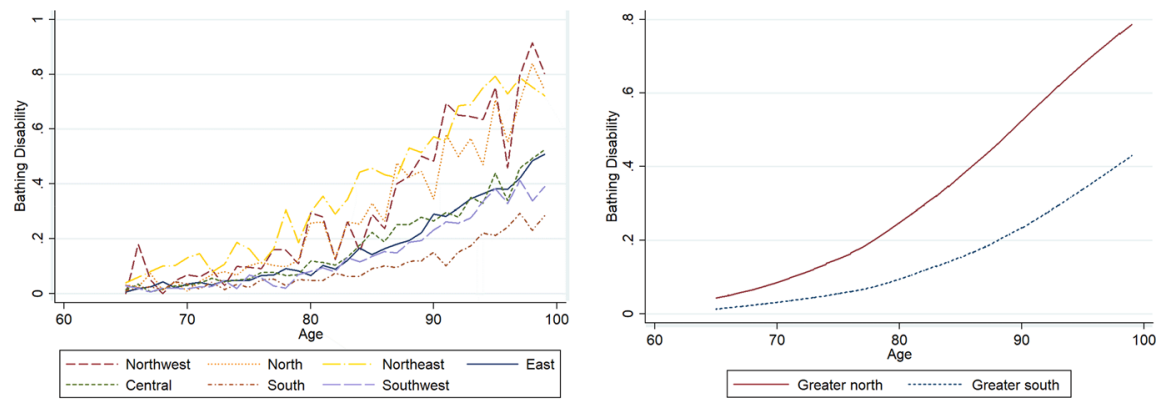

Fig. 1 Prevalence of bathing disability among older adults across seven regions in China (weighted) 

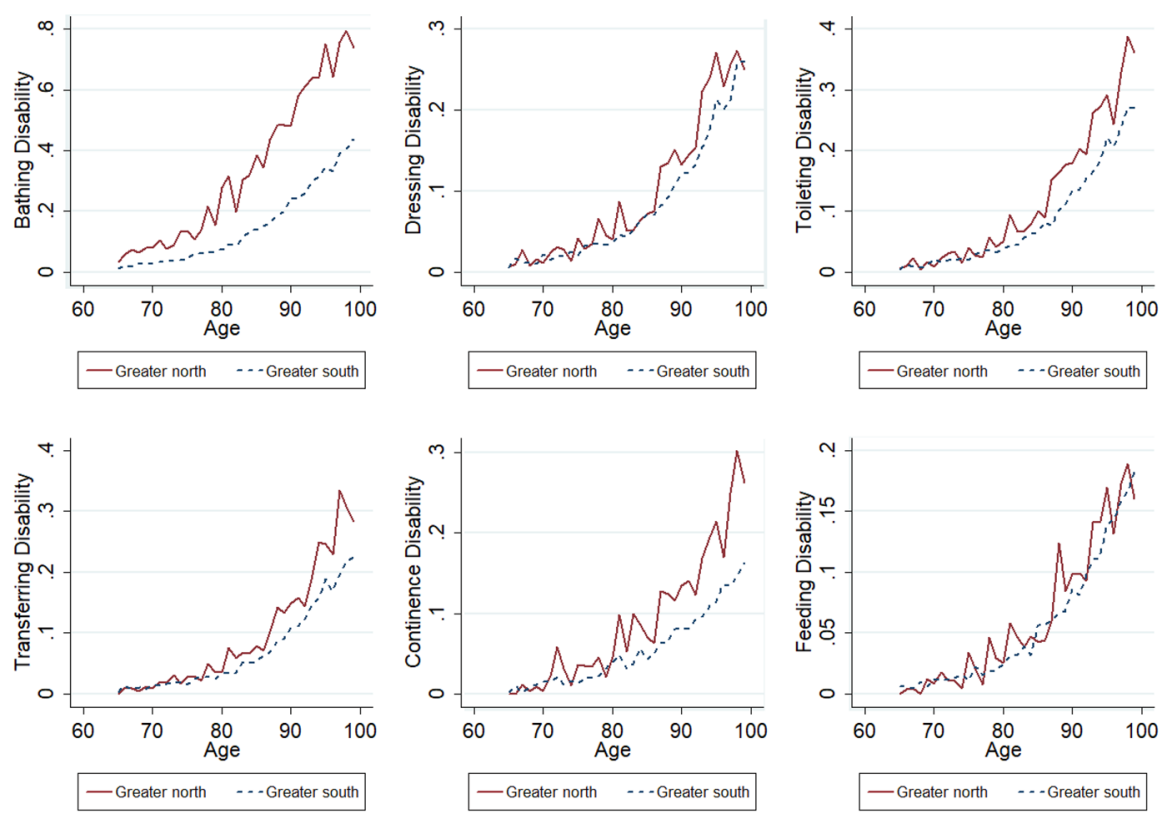

Fig. 2 Comparison of five ADL disability prevalence between the two greater regions (weighted)

$(p<0.001)$ after controlling for various sociodemographic variables and the odds ratios is as large as about 6 . The odds ratio was increased slightly to around 7.5 after controlling for health status variables in Model II and adding on health behavior variables in Model III. In other words, an older adult residing in Northern China is about 7.5 times more likely to encounter difficulty in bathing, as compared to an individual from Southern China. Results of covariates were mostly as expected. Being older, being a woman, and living in an urban residence were associated with higher odds of experiencing bathing disability; good health statuses and health behavior reduced the risk of experiencing bathing disability in later life. To increase the robustness of the results, two alternative categorizations of regions were also tested using Yangtze River as an approximate midpoint. The results, as presented in Appendix A (Supplementary material), are found to be largely similar to the results using the original categorization, which indicated that older adults residing in northern regions are more likely to experience bathing disabilities compared to those in the south. An additional analysis presented in Appendix B (Supplementary material) shows that the regional disparity persisted even after controlling for the other 5 ADL items.

We further examined this pattern by age and gender groups (Table 4). Overall, regardless of age group or gender, the regional disparity remains salient. However, it was notable that the previously observed regional disparity was larger for women and the oldest-old group. An oldest-old woman residing in the greater north, for example, is around 9.8 times more likely to experience bathing disability when compared to her southern counterpart. 
Table 3 Stepwise regression showing odds ratio of bathing disability in older adults (Age 65-99)

\begin{tabular}{|c|c|c|c|}
\hline & Model I & Model II & Model III \\
\hline \multicolumn{4}{|l|}{ Sociodemographic variables } \\
\hline Age & $1.18 * * *$ & $1.10 * * *$ & $1.09 * * *$ \\
\hline Women (Men) & $1.53 * * *$ & $1.16^{* * *}$ & $1.17 * * *$ \\
\hline Rural residence (Urban) & $0.72 * * *$ & $0.68 * * *$ & $0.61 * * *$ \\
\hline Years of education & $0.98 * * *$ & 1.00 & $1.03 * * *$ \\
\hline Occupational prestige & $1.01 * * *$ & $1.01 * * *$ & $1.02 * * *$ \\
\hline Log of household income & 1.05 & $1.22 * * *$ & $1.34 * * *$ \\
\hline Married (Not married) & 0.92 & 1.04 & 1.07 \\
\hline Number of coresidents & $1.07 * * *$ & $1.06 * * *$ & $1.06 * * *$ \\
\hline \multicolumn{4}{|l|}{ North-South } \\
\hline Greater north (Greater south) & $6.02 * * *$ & $6.52 * * *$ & $7.57 * * *$ \\
\hline \multicolumn{4}{|l|}{ Health status variables } \\
\hline Negative well-being (No) & & $1.19 * * *$ & $1.14 * * *$ \\
\hline Cognitively impaired (No) & & $3.02 * * *$ & $2.50 * * *$ \\
\hline Upper limb functionally limited (No) & & $3.92 * * *$ & $3.76 * * *$ \\
\hline Lower limb functionally limited (No) & & $7.33 * * *$ & $6.32 * * *$ \\
\hline \multicolumn{4}{|l|}{ Health behavior variables } \\
\hline Eats vegetables and fruits regularly (No) & & & $0.91 *$ \\
\hline Exercises regularly (No) & & & $0.57 * * *$ \\
\hline Engages in leisure activities (No) & & & $0.68 * * *$ \\
\hline Current or past smoker (No) & & & $1.19 * * *$ \\
\hline $\mathrm{P}$ & 0.48 & 0.37 & 0.38 \\
\hline Number of observations & 79,640 & 79,640 & 79,640 \\
\hline Number of individuals & 42,801 & 42,801 & 42,801 \\
\hline
\end{tabular}

$* p<0.05, * * p<0.01, * * * p<0.001$

Table 5 further investigates this pattern by seven regions. After breaking down the two greater regions into seven smaller regions, the results of the Northeast region stood out among the rest. Specifically, an oldest-old woman residing in the Northeast region was around 36 times more likely to experience bathing disability compared to her counterpart from the South. This was closely followed by the other northern regions, with an odds ratio of around 22 for the Northwest, and about 15 for the North. In comparison, for the other three regions in the greater south, the odds ratios were relatively lower: An oldest-old woman residing in the East and Central regions was around 3 times more likely to experience bathing disability compared to the South, while this number declines to around 2.5 for the Southwest. 
Table 4 Odds ratio of bathing disability by gender and age group with north-south variable

\begin{tabular}{|c|c|c|c|c|}
\hline & \multicolumn{2}{|l|}{ Men } & \multicolumn{2}{|l|}{ Women } \\
\hline & Ages $65-79$ & Ages 80-99 & Ages 65-79 & Ages 80-99 \\
\hline \multicolumn{5}{|l|}{ Sociodemographic variables } \\
\hline Age & $1.08 * * *$ & $1.09 * * *$ & $1.08 * * *$ & $1.10^{* * *}$ \\
\hline Rural residence (Urban) & $0.60 * * *$ & $0.58 * * *$ & $0.56^{* * *}$ & $0.66^{* * * *}$ \\
\hline Years of education & 1.04 & $1.04 * * *$ & 1.04 & $1.03^{*}$ \\
\hline Occupational prestige & 1.01 & $1.02 * * *$ & 1.02 & $1.03 * * *$ \\
\hline Log of household income & $1.45^{* *}$ & $1.4 * * *$ & 1.18 & $1.32 * * *$ \\
\hline Married (Not married) & $1.61 * *$ & $1.14 *$ & 0.99 & 0.92 \\
\hline Number of coresidents & 1.01 & $1.05^{* * *}$ & $1.11^{* * *}$ & $1.06^{* * *}$ \\
\hline \multicolumn{5}{|l|}{ North-South } \\
\hline Greater north (Greater south) & $3.78^{* * *}$ & $6.74 * * *$ & $6.40^{* * *}$ & $9.83 * * *$ \\
\hline \multicolumn{5}{|l|}{ Health status variables } \\
\hline Negative well-being (No) & $1.35^{* * *}$ & $1.14 * * *$ & $1.29 * * *$ & $1.1^{* * *}$ \\
\hline Cognitively impaired (No) & $3.94 * * *$ & $2.77 * * *$ & $4.02 * * *$ & $2.34 * * *$ \\
\hline Upper limb functionally limited (No) & $6.02 * * *$ & $3.39 * * *$ & $5.03 * * *$ & $3.61 * * *$ \\
\hline Lower limb functionally limited (No) & $11.64 * * *$ & $6.39 * * *$ & $7.35 * * *$ & $5.75 * * *$ \\
\hline \multicolumn{5}{|l|}{ Health behavior variables } \\
\hline Eats vegetables and fruits regularly (No) & 0.72 & $0.77 * * *$ & 0.80 & 1.04 \\
\hline Exercises regularly (No) & $0.54 * * *$ & $0.55 * * *$ & $0.60 * * *$ & $0.62 * * *$ \\
\hline Engages in leisure activities (No) & $0.56 * * *$ & $0.70 * * *$ & $0.64 * * *$ & $0.7 * * *$ \\
\hline Current or past smoker (No) & 1.11 & $1.12 *$ & 1.15 & $1.27 * * *$ \\
\hline $\mathrm{P}$ & 0.42 & 0.35 & 0.40 & 0.38 \\
\hline Number of observations & 12,419 & 25,670 & 11,783 & 29,767 \\
\hline Number of individuals & 6,741 & 15,241 & 6,400 & 17,540 \\
\hline
\end{tabular}

$* p<0.05, * * p<0.01, * * * p<0.001$

\section{Discussion}

Bathing is a major type of disability among older adults and it deserves more research attention, given the rapid population aging around the world. To our knowledge, this study is the first to explore the regional disparity of bathing disability among older adults in China. Overall, we found that older adults living in the northern regions were more likely to experience bathing disability, even after controlling for various sociodemographic, health status, and health behavior variables at the individual level. We also observed that this regional disparity was more substantial for the women and oldest-old. A deeper investigation into the differences between the seven regions nestled within the north-south divide further revealed that older adults residing in the Northeast stand out for having the highest likelihood of experiencing bathing disability. The findings of this study have important theoretical and practical implications. 
Table 5 Odds ratio of bathing disability by gender and age group with region variable

\begin{tabular}{|c|c|c|c|c|}
\hline & \multicolumn{2}{|l|}{ Men } & \multicolumn{2}{|l|}{ Women } \\
\hline & Ages 65-79 & Ages 80-99 & Ages $65-79$ & Ages 80-99 \\
\hline \multicolumn{5}{|l|}{ Sociodemographic variables } \\
\hline Age & $1.08 * * *$ & $1.09 * * *$ & $1.08 * * *$ & $1.10 * * *$ \\
\hline Rural residence (Urban) & $0.6^{* * * *}$ & $0.59 * * *$ & $0.56^{* * *}$ & $0.67 * * *$ \\
\hline Years of education & 1.04 & $1.05 * * *$ & 1.04 & $1.05 * * *$ \\
\hline Occupational prestige & 1.01 & $1.02 * * *$ & 1.02 & $1.02 * * *$ \\
\hline Log of household income & $1.41 *$ & $1.34 * *$ & 1.12 & $1.26 * * *$ \\
\hline Married (Not married) & $1.53 * *$ & $1.14 *$ & 0.97 & 0.90 \\
\hline Number of coresidents & 1.04 & $1.07 * * *$ & $1.14 * * *$ & $1.09 * * *$ \\
\hline \multicolumn{5}{|l|}{ Region } \\
\hline Northwest (South) & $2.70^{*}$ & $11.39 * * *$ & $9.04 * * *$ & $22.38 * * *$ \\
\hline North (South) & $3.24 * * *$ & $11.36^{* * * *}$ & $5.57 * * *$ & $14.96 * * *$ \\
\hline Northeast (South) & $9.37 * * *$ & $22.45 * * *$ & $18.09 * * *$ & $36.18 * * *$ \\
\hline East (South) & $1.82 * *$ & $3.11 * * *$ & $2.36 * * *$ & $3.31 * * *$ \\
\hline Central (South) & 1.33 & $2.75 * * *$ & $2.72 * * *$ & $2.96 * * *$ \\
\hline Southwest (South) & $1.93 *$ & $2.50 * * *$ & 1.17 & $2.59 * * *$ \\
\hline \multicolumn{5}{|l|}{ Health status variables } \\
\hline Negative well-being (No) & $1.33 * * *$ & $1.14 * * *$ & $1.27 * * *$ & $1.10 * * *$ \\
\hline Cognitively impaired (No) & $4.00 * * *$ & $2.76^{* * *}$ & $4.14 * * *$ & $2.33 * * *$ \\
\hline Upper limb functionally limited (No) & $6.01 * * *$ & $3.37 * * *$ & $4.92 * * *$ & $3.59 * * *$ \\
\hline Lower limb functionally limited (No) & $11.99 * * *$ & $6.42 * * *$ & $7.42 * * *$ & $5.77 * * *$ \\
\hline \multicolumn{5}{|l|}{ Health behavior variables } \\
\hline Eats vegetables and fruits regularly (No) & 0.73 & $0.77 * * *$ & 0.83 & 1.04 \\
\hline Exercises regularly (No) & $0.52 * * *$ & $0.55 * * *$ & $0.62 * *$ & $0.63 * * *$ \\
\hline Engages in leisure activities (No) & $0.56 * * *$ & $0.70 * * *$ & $0.64 * * *$ & $0.71 * * *$ \\
\hline Current or past smoker (No) & 1.09 & $1.12 *$ & 1.09 & $1.18^{*}$ \\
\hline $\mathrm{P}$ & 0.42 & 0.34 & 0.38 & 0.35 \\
\hline Number of observations & 12,419 & 25,670 & 11,783 & 29,767 \\
\hline Number of individuals & 6,741 & 15,241 & 6,400 & 17,540 \\
\hline
\end{tabular}

$* p<0.05, * * p<0.01, * * * p<0.001$

The literature on bathing disability has long acknowledged the role of the environment; yet most studies have focused only on the built environments, especially within the bathroom itself such as bathroom adaptations and furniture (Burton et al., 2011; Whitehead \& Golding-Day, 2019). This study thus sheds new light in the field by highlighting the importance of external factors in affecting the bathing capability of older adults. Consistent with the findings of an earlier study which noted that low seasonal temperatures may increase ADL disability of older Chinese (Zeng et al., 2010), we further uncovered that older adults living in colder regions of China are overwhelmingly more likely to experience bathing disability than those living in warmer regions. 
With regard to the interesting regional disparity observed in this study, we think there could be at least two possible reasons: climate and economic development. First, the colder climate in the north may pose additional challenges for older adults in bathing, especially for those facing chronic health conditions or mobility issues (Liu et al., 2020). Bathing is highly environment-dependent, as low temperatures may cause discomforts and could even expose older adults to multiple health risks such as catching a cold or feeling excessively cold. This is particularly true in the winter of Northern China. Such disadvantageous conditions may disincentivize bathing for older people, who may instead seek alternative ways of cleansing, leading to the high prevalence in the reporting of bathing difficulties among older residents.

Next, the uneven economic development across China could be another important factor in explaining the regional disparity of bathing difficulty. Since the 1970s, the coastal regions of China, mainly those in the Eastern and Southern provinces, have become more economically developed than the rest of China, due to the huge foreign investments and related exports (Han \& Yan, 1999; Risso \& Carrera, 2012; Tzeng, 1991). The stages of economic development may directly impact the availability of modern bathing facilities in the households such as indoor shower rooms, heating devices, or bathtubs. Thus, it is more likely for people in the developed regions to have access to these facilities and report fewer difficulties in bathing. The impact of economic development could also be supported by our empirical analyses within the regions. The highest odds ratio for the Northeast region matched well with the fact that this region has experienced significant economic slowdown and depopulation over recent years (Yang et al., 2019; You et al., 2021).

Asides from the two reasons discussed above, it is important to note that there could be other additional factors affecting the regional disparity in bathing disability. Previous studies have established that there can be variations in the types of bathing facilities available especially in rural China (Liu et al., 2020). Coupled with the finding from the $20051 \%$ mini census, which found that a larger proportion of households from the greater north area lacked indoor bathing facilities compared to households from the greater south, this may partially explain the higher rates of bathing disabilities experienced by residents in the greater north due to the colder climate. Similarly, living arrangements and the need to use shared facilities with other households have been identified in another study as affecting ADL disabilities for urban residents (Fong \& Feng, 2021). Furthermore, personal bathing habits may be informed by local customs, culture, or religious beliefs (Lei, 2009), which could in turn contribute to regional differences in bathing frequency, or the expression of bathing difficulty as well. Nevertheless, there are significant differences in the climate and economic development between the different regions, which is likely to play a contributory role in the regional disparity in bathing disability.

It is interesting to note that the regional disparity primarily only applied to bathing disability and not the other ADLs. Simultaneously, this also indicates a huge potential for policy and interventions to improve the bathing difficulties among Chinese older adults. The importance of improving bathing conditions for older adults should not be understated. Bathing is usually the earliest task that older adults become unable to accomplish independently (Chalise et al., 2008; Mlinac \& Feng, 
2016; Reynolds \& Silverstein, 2003) and consequently, it tends to be significantly more prevalent than the other ADL items amongst older adults (Millán-Calenti et al., 2010; Purser et al., 2012). Beyond the concerns of cleansing oneself, bathing also serves a wider social purpose in promoting self-esteem and social acceptance (Lentz, 2003). Ahluwalia et al. (2010) reported that for older adults, bathing is not only important in enabling social interactions as it maintains the upkeep of personal hygiene, but it also creates a sense of routine in daily lives. Bathing is therefore a precondition for older adults to maintain dignity in their later lives. Furthermore, having the capacity to bathe in older ages may also prevent social withdrawals and improve the well-being of older adults (Luo \& Waite, 2014).

The findings of this study call for public policy interventions to be implemented in this area, which is exactly in line with China's recent Active Response to Population Aging Strategy under the 14th 5-year plan (2021-2025) to develop an agingfriendly community (Xinhua News Agency, 2021). Along the same line, we firstly propose that current disability research needs to move towards analyses on specific disability items, instead of only sticking to the undifferentiated ADL or IADL index, as the recognition of unique risk factors of each specific disability could be more effectively tackled with targeted environmental modifications or policy changes (Fong \& Feng, 2021). As illustrated in this study, older adults living in the Northern regions, especially those in the Northeast, should receive special attention from the government in regard to promoting bathing conditions. In addition, they should also concentrate their efforts on women and the oldest-old, as they are the demographic group that is more likely to face bathing difficulties according to our empirical findings. Specifically, we think that some feasible measures for policy interventions could be to target the bathroom facilities of older residents such as the addition of heating facilities for regions with freezing temperatures in the winters as well as introducing safety instruments such as grab rails.

There were several limitations in this study. Pertaining to the limitations of the questionnaire design, CLHLS did not make a clear distinction between bathing and showering, treating it as the same activity, even though there could be some qualitative differences in the movement involved in bathing and showering. CLHLS also did not collect detailed information on whether the bathing difficulties were experienced only in the winter months or throughout the year, which would have helped to clarify whether there were cyclical effects affecting bathing disability. It is possible that bathing frequency and the types of difficulties faced could differ between the summer and winter seasons (Yagi et al., 2019), and future studies could seek to address that as well. Furthermore, while CLHLS is nationally representative, that is not the case at the regional level, and there could be regional biases. It should also be noted that the sampling frame of CLHLS is different across waves, making it less viable for health trend analysis (see Gu et al., 2021), though that is not the focus of this study. Additionally, there was a slight change in how questions about ADL were asked from the fifth wave of the survey onwards, though based on our preliminary analysis, that did not significantly impact the results. Beyond issues on survey design, another limitation was that in examining the regional disparity, we did not try to differentiate between the effects of climate and socioeconomic developments. Future studies therefore could seek to understand this better by comparing with data 
that are more fine-grained, such as those that show the types of bathroom facilities that are available and combine with provincial specific data that includes temperature, altitudes, and other geographical factors. Furthermore, future studies could also seek to incorporate longitudinal explorations of bathing disability trends to better understand its trajectories across time.

Supplementary Information The online version contains supplementary material available at https://doi. org/10.1007/s42379-021-00097-3.

Data availability statement The data is from the Chinese Longitudinal Healthy Longevity Survey, which is publicly available.

\section{Declarations}

Conflict of interest The authors declare there is no conflict of interest.

Open Access This article is licensed under a Creative Commons Attribution 4.0 International License, which permits use, sharing, adaptation, distribution and reproduction in any medium or format, as long as you give appropriate credit to the original author(s) and the source, provide a link to the Creative Commons licence, and indicate if changes were made. The images or other third party material in this article are included in the article's Creative Commons licence, unless indicated otherwise in a credit line to the material. If material is not included in the article's Creative Commons licence and your intended use is not permitted by statutory regulation or exceeds the permitted use, you will need to obtain permission directly from the copyright holder. To view a copy of this licence, visit http://creativecommons.org/licen ses/by/4.0\%.

\section{References}

Ahluwalia, S. C., Gill, T. M., Baker, D. I., \& Fried, T. R. (2010). Perspectives of older persons on bathing and bathing disability: a qualitative study. Journal of the American Geriatrics Society, 58(3), 450-456. https://doi.org/10.1111/j.1532-5415.2010.02722.x

Ambler, G., Omar, R. Z., \& Royston, P. (2007). A comparison of imputation techniques for handling missing predictor values in a risk model with a binary outcome. Statistical Methods in Medical Research, 16(3), 277-298. https://doi.org/10.1177/0962280206074466

Aminzadeh, F., Edwards, N., Lockett, D., \& Nair, R. C. (2001). Utilization of bathroom safety devices, patterns of bathing and toileting, and bathroom falls in a sample of community living older adults. Technology and Disability, 13(2), 95-103. https://doi.org/10.3233/tad-2000-13202

Azur, M. J., Stuart, E. A., Frangakis, C., \& Leaf, P. J. (2011). Multiple imputation by chained equations: what is it and how does it work? International Journal of Methods in Psychiatric Research, 20(1), 40-49. https://doi.org/10.1002/mpr.329

Balfour, J. L., \& Kaplan, G. J. (2002). Neighborhood environment and loss of physical function in older adults: Evidence from the Alameda County Study. American Journal of Epidemiology, 155(6), 507515. https://doi.org/10.1093/aje/155.6.507

Burton, M., Reed, H., \& Chamberlain, P. (2011). Age-related disability and bathroom use. Journal of Integrated Care, 19(1), 37-43. https://doi.org/10.5042/jic.2011.0034

Chalise, H. N., Saito, T., \& Kai, I. (2008). Functional disability in activities of daily living and instrumental activities of daily living among Nepalese Newar elderly. Public Health, 122(4), 394-396. https:// doi.org/10.1016/j.puhe.2007.07.015

Chen, L., Zhang, X., \& Xu, X. (2020). Health insurance and long-term care services for the disabled elderly in China: based on CHARLS data. Risk Management and Healthcare Policy, 13, 155-162. https://doi.org/10.2147/RMHP.S233949 
Cohen-Mansfield, J., \& Parpura-Gill, A. (2007). Bathing: A framework for intervention focusing on psychosocial, architectural, and human factors considerations. Archives of Gerontology and Geriatrics, 45(2), 121-135. https://doi.org/10.1016/j.archger.2006.09.001

De-Rosende-Celeiro, I., Torres, G., Seoane-Bouzas, M., \& Ávila, A. (2019). Exploring the use of assistive products to promote functional independence in self-care activities in the bathroom. PLoS ONE. https://doi.org/10.1371/journal.pone.0215002

Feng, Q., Zhen, Z., Gu, D., Wu, B., Duncan, P. W., \& Purser, J. L. (2013). Trends in ADL and IADL disability in community-dwelling older adults in Shanghai, China, 1998-2008. Journals of Gerontology Series B Psychological Sciences and Social Sciences, 68(3), 476-485. https://doi.org/10.1093/ geronb/gbt012

Fong, J. H., \& Feng, Q. (2021). Toileting disability among older adults in china and role of environmental factors. Journal of Aging and Health. https://doi.org/10.1177/08982643211015026

Freedman, V. A., Grafova, I. B., Schoeni, R. F., \& Rogowski, J. (2008). Neighborhoods and disability in later life. Social Science and Medicine, 66(11), 2253-2267. https://doi.org/10.1016/j.socscimed. 2008.01.013

Gao, M., Kuang, W., Qiu, P., Wang, H., Lv, X., \& Yang, M. (2017). The time trends of cognitive impairment incidence among older Chinese people in the community: based on the CLHLS cohorts from 1998 to 2014. Age and Ageing, 46(5), 787-793. https://doi.org/10.1093/ageing/afx038

Gill, T. M., Han, L., \& Allore, H. G. (2007). Bath aids and the subsequent development of bathing disability in community-living older persons. Journal of the American Geriatrics Society, 55(11), 1757-1763. https://doi.org/10.1111/j.1532-5415.2007.01421.x

Gu, D., \& Xu, Q. (2007). Sociodemographic effects on the dynamics of task-specific ADL functioning at the oldest-old ages: the case of China. Journal of Cross-Cultural Gerontology, 22(1), 61-81. https:// doi.org/10.1007/s10823-006-9024-0

Gu, D., \& Zeng, Y. (2004). Sociodemographic effects on the onset and recovery of ADL disability among Chinese oldest-old. Demographic Research, 11(1), 1-41. https://doi.org/10.4054/demres.2004.11.1

Gu, D., Feng, Q., Chen, H., \& Zeng, Y. (2021) Chinese Longitudinal Healthy Longevity Survey (CLHLS). In D. Gu \& M.E. Dupre (Eds.), Encyclopedia of Gerontology and Population Aging. Springer. https://doi.org/10.1007/978-3-319-69892-2_968-1

Han, S. S., \& Yan, Z. (1999). China's coastal cities: Development, planning and challenges. Habitat International, 23(2), 217-229. https://doi.org/10.1016/S0197-3975(98)00046-0

He, S., Bayrak, M. M., \& Lin, H. (2017). A comparative analysis of multi-scalar regional inequality in China. Geoforum, 78, 1-11. https://doi.org/10.1016/j.geoforum.2016.10.021

Hoh, J. W. T., Lu, S., Feng, Q., \& Gu, D. (2021). Longevity areas and mass longevity. In D. Gu \& M.E. Dupre (Eds.), Encyclopedia of Gerontology and Population Aging. Springer. https://doi.org/10. 1007/978-3-319-69892-2_1128-1

Hua, L. J., Ma, Z. G., \& Guo, W. D. (2008). The impact of urbanization on air temperature across China. Theoretical and Applied Climatology, 93(3-4), 179-194. https://doi.org/10.1007/ s00704-007-0339-8

Iwarsson, S. (2005). A long-term perspective on person-environment fit and ADL dependence among older Swedish adults. The Gerontologist, 45(3), 327-336. https://doi.org/10.1093/geront/45.3.327

Jagger, C., Arthur, A. J., Spiers, N. A., \& Clarke, M. (2001). Patterns of onset of disability in activities of daily living with age. Journal of the American Geriatrics Society, 49(4), 404-409. https://doi.org/ 10.1046/j.1532-5415.2001.49083.x

Katz, S., \& Akpom, C. A. (1976). A measure of primary sociobiological functions. International Journal of Health Services, 6(3), 493-508. https://doi.org/10.2190/UURL-2RYU-WRYD-EY3K

Katz, S., Ford, A. B., Moskowitz, R. W., Jackson, B. A., \& Jaffe, M. W. (1963). Studies of illness in the aged-the Index of ADL: a standardized measure of biological and psychosocial function. JAMA, 185(12), 914-919. https://doi.org/10.1001/jama.1963.03060120024016

Lei, S. H. (2009). Moral community of Weisheng: contesting hygiene in Republican China. East Asian Science, Technology and Society, 3(4), 475-504. https://doi.org/10.1007/s12280-009-9109-2

Lentz, J. (2003). Daily baths: Torment or comfort at end of life? Journal of Hospice and Palliative Nursing, 5(1), 34-39. https://doi.org/10.1097/00129191-200301000-00017

Lim, Y. M., Kim, H., \& Cha, Y. J. (2020). Effects of environmental modification on activities of daily living, social participation and quality of life in the older adults: a meta-analysis of randomized controlled trials. Disability and Rehabilitation: Assistive Technology, 15(2), 132-140. https://doi.org/ 10.1080/17483107.2018.1533595 
Liu, J., \& Zhang, Y. (2019). Health status and health disparity in China: a demographic and socioeconomic perspective. China Population and Development Studies, 2(3), 301-322. https://doi.org/10. 1007/s42379-018-0015-y

Liu, C., Fong, J. H., Hoh, J. W. T., Wu, H., Dong, Y., Gu, D., \& Feng, Q. (2020). Bathing and toileting difficulties of older adults in rural China: the role of environment. BMC Geriatrics, 20(1), 1-9. https://doi.org/10.1186/s12877-020-01919-8

Luo, Y., \& Waite, L. J. (2014). Loneliness and mortality among older adults in China. Journals of Gerontology Series B Psychological Sciences and Social Sciences, 69(4), 633-645. https://doi.org/10. 1093/geronb/gbu007

Lv, Y. B., Yuan, J. Q., Mao, C., Gao, X., Yin, Z. X., Kraus, V. B., Luo, J. S., Chen, H. S., Zeng, Y., Wang, W. T., Wang, J. N., \& Shi, X. M. (2018). Association of body mass index with disability in activities of daily living among chinese adults 80 years of age or older. JAMA Network Open, 1(5), e181915. https://doi.org/10.1001/jamanetworkopen.2018.1915

Lv, Y., Zhou, J., Kraus, V. B., Li, T., Sarnat, J. A., Wang, J., Liu, Y., Chen, H., Brasher, M. S., Mao, C., Zeng, Y., Zheng, T., \& Shi, X. (2020). Long-term exposure to PM2.5 and incidence of disability in activities of daily living among oldest old. Environmental Pollution. https://doi.org/10.1016/j. envpol.2020.113910

Millán-Calenti, J. C., Tubío, J., Pita-Fernández, S., González-Abraldes, I., Lorenzo, T., Fernández-Arruty, T., \& Maseda, A. (2010). Prevalence of functional disability in activities of daily living (ADL), instrumental activities of daily living (IADL) and associated factors, as predictors of morbidity and mortality. Archives of Gerontology and Geriatrics, 50(3), 306-310. https://doi.org/10.1016/j.archg er.2009.04.017

Mlinac, M. E., \& Feng, M. C. (2016). Assessment of activities of daily living, self-care, and independence. Archives of Clinical Neuropsychology, 31(6), 506-516. https://doi.org/10.1093/arclin/acw049

Monma, T., Takeda, F., Noguchi, H., Takahashi, H., \& Tamiya, N. (2016). The impact of leisure and social activities on activities of daily living of middle-aged adults: evidence from a national longitudinal survey in Japan. PLoS ONE. https://doi.org/10.1371/journal.pone.0165106

Moskalev, A. A., Aliper, A. M., Smit-McBride, Z., Buzdin, A., \& Zhavoronkov, A. (2014). Genetics and epigenetics of aging and longevity. Cell Cycle, 13(7), 1063-1077. https://doi.org/10.4161/cc.28433

Murphy, S. L., Gretebeck, K. A., \& Alexander, N. B. (2007). The bath environment, the bathing task, and the older adult: a review and future directions for bathing disability research. Disability and Rehabilitation, 29(14), 1067-1075. https://doi.org/10.1080/09638280600950694

Naik, A. D., \& Gill, T. M. (2005). Underutilization of environmental adaptations for bathing in community-living older persons. Journal of the American Geriatrics Society, 53(9), 1497-1503. https://doi. org/10.1111/j.1532-5415.2005.53458.x

National Bureau of Statistics of China. (2021). Main data of the seventh national population census [Press release]. http://www.stats.gov.cn/english/PressRelease/202105/t20210510_1817185.html

Purser, J. L., Feng, Q., Yi, Z., \& Hoenig, H. (2012). A new classification of function and disability in China: subtypes based on performance-based and self-reported measures. Journal of Aging and Health, 24(5), 779-798. https://doi.org/10.1177/0898264312444310

Rader, J., Barrick, A. L., Hoeffer, B., Sloane, P. D., McKenzie, D., Talerico, K. A., \& Glover, J. U. (2006). The bathing of older adults with dementia. Easing the unnecessarily unpleasant aspects of assisted bathing. American Journal of Nursing, 106(4), 40-49. https://doi.org/10.1097/00000446200604000-00026

Reynolds, S. L., \& Silverstein, M. (2003). Observing the onset of disability in older adults. Social Science and Medicine, 57(10), 1875-1889. https://doi.org/10.1016/S0277-9536(03)00053-4

Risso, W. A., \& Carrera, E. J. S. (2012). Inequality and economic growth in China. Journal of Chinese Economic and Foreign Trade Studies, 5(2), 80-90. https://doi.org/10.1108/17544401211233453

Shen, H., Teng, F., \& Song, J. (2018). Evaluation of spatial balance of China's regional development. Sustainability (switzerland). https://doi.org/10.3390/su10093314

Si, P., Zheng, Z., Ren, Y., Liang, D., Li, M., \& Shu, W. (2014). Effects of urbanization on daily temperature extremes in North China. Journal of Geographical Sciences, 24(2), 349-362. https://doi.org/10. 1007/s11442-014-1092-4

Sun, R. (2021). double jeopardy versus double benefit: the role of age and leisure activities in the incidence of disability among Chinese older adults. Journal of Aging and Health, 33(5-6), 350-361. https://doi.org/10.1177/0898264320983660

Tan, X., Liu, X., \& Shao, H. (2017). Healthy China 2030: a vision for health care. Value in Health Regional Issues, 12, 112-114. https://doi.org/10.1016/j.vhri.2017.04.001 
Treiman, D. J. (1977). Occupational prestige in comparative perspective. Academic Press.

Tzeng, F. W. (1991). The political economy of china's coastal development strategy: a preliminary analysis. Asian Survey, 31(3), 270-284. https://doi.org/10.2307/2645245

Vacante, M., Dagata, V., Motta, M., Malaguarnera, G., Biondi, A., Basile, F., Malaguarnera, M., Gagliano, C., Drago, F., \& Salamone, S. (2012). Centenarians and supercentenarians: a black swan. Emerging social, medical and surgical problems. BMC Surgery. https://doi.org/10.1186/ 1471-2482-12-S1-S36

Verbrugge, L. M., \& Jette, A. M. (1994). The disablement process. Social Science and Medicine, 38(1), 1-14. https://doi.org/10.1016/0277-9536(94)90294-1

Waidmann, T. A., \& Liu, K. (2000). Disability trends among elderly persons and implications for the future. Journals of Gerontology Series B Psychological Sciences and Social Sciences, 55(5), 298307. https://doi.org/10.1093/geronb/55.5.S298

Whitehead, P. J., \& Golding-Day, M. R. (2019). The lived experience of bathing adaptations in the homes of older adults and their carers (BATH-OUT): a qualitative interview study. Health and Social Care in the Community, 27(6), 1534-1543. https://doi.org/10.1111/hsc.12824

World Health Organization. (2011). World report on disability 2011. https://apps.who.int/iris/handle/ $10665 / 44575$

World Health Organization. (2015). World report on ageing and health. https://apps.who.int/iris/handle/ $10665 / 186463$

Wu, Y., Song, Y., \& Yu, T. (2019). Spatial differences in China's population aging and influencing factors: The perspectives of spatial dependence and spatial heterogeneity. Sustainability (Switzerland), 11(21). https://doi.org/10.3390/su11215959

Xinhua News Agency. (2021). The People's Republic of China's economic and social development $14^{\text {th }}$ 5-year plan and outline of the 2035 vision. http://www.gov.cn/xinwen/2021-03/13/content_55926 81.htm

Yagi, A., Hayasaka, S., Ojima, T., Sasaki, Y., Tsuji, T., Miyaguni, Y., Nagamine, Y., Namiki, T., \& Kondo, K. (2019). Bathing frequency and onset of functional disability among japanese older adults: a prospective 3-year cohort study from the JAGES. Journal of Epidemiology, 29(12), 451456. https://doi.org/10.2188/jea.JE20180123

Yang, L., Zhao, K., \& Fan, Z. (2019). Exploring determinants of population ageing in northeast China: From a socio-economic perspective. International Journal of Environmental Research and Public Health. https://doi.org/10.3390/ijerph16214265

Yin, S., Yang, Q., Xiong, J., Li, T., \& Zhu, X. (2020). Social support and the incidence of cognitive impairment among older adults in China: findings from the Chinese longitudinal healthy longevity survey study. Frontiers in Psychiatry. https://doi.org/10.3389/fpsyt.2020.00254

You, H., Yang, J., Xue, B., Xiao, X., Xia, J., Jin, C., \& Li, X. (2021). Spatial evolution of population change in Northeast China during 1992-2018. Science of the Total Environment. https://doi.org/10. 1016/j.scitotenv.2021.146023

Yu, J., Li, J., Cuijpers, P., Wu, S., \& Wu, Z. (2012). Prevalence and correlates of depressive symptoms in Chinese older adults: a population-based study. International Journal of Geriatric Psychiatry, 27(3), 305-312. https://doi.org/10.1002/gps.2721

Zeng, Y. (2012). Toward deeper research and better policy for healthy aging - using the unique data of Chinese longitudinal healthy longevity survey. China Economic Journal, 5(2-3), 131-149. https:// doi.org/10.1080/17538963.2013.764677

Zeng, Y., Feng, Q., Hesketh, T., Christensen, K., \& Vaupel, J. W. (2017). Survival, disabilities in activities of daily living, and physical and cognitive functioning among the oldest-old in China: a cohort study. The Lancet, 389(10079), 1619-1629. https://doi.org/10.1016/S0140-6736(17)30548-2

Zeng, Y., Gu, D., Purser, J., Hoenig, H., \& Christakis, N. (2010). Associations of environmental factors with elderly health and mortality in china. American Journal of Public Health, 100(2), 298-305. https://doi.org/10.2105/AJPH.2008.154971

Zhang, W., \& Feldman, M. W. (2020). Disability trajectories in activities of daily living of elderly Chinese before death. China Population and Development Studies, 4(2), 127-151. https://doi.org/10. 1007/s42379-020-00063-5

Zhang, Z. (2006). Gender differentials in cognitive impairment and decline of the oldest old in China. Journals of Gerontology Series B Psychological Sciences and Social Sciences. https://doi.org/10. 1093/geronb/61.2.S107 
Zhang, Z., Gu, D., \& Hayward, M. D. (2008). Early life influences on cognitive impairment among oldest old Chinese. Journals of Gerontology - Series B Psychological Sciences and Social Sciences. https://doi.org/10.1093/geronb/63.1.S25

Zhu, X., Qiu, C., Zeng, Y., \& Li, J. (2017). Leisure activities, education, and cognitive impairment in Chinese older adults: a population-based longitudinal study. International Psychogeriatrics, 29(5), 727-739. https://doi.org/10.1017/S1041610216001769 